\title{
Factors associated with contralateral preventive mastectomy
}

\author{
This article was published in the following Dove Press journal: \\ Breast Cancer: Targets and Therapy \\ 7 January 2015 \\ Number of times this article has been viewed
}

\author{
Danny Yakoub ${ }^{1,2}$ \\ Eli Avisar ${ }^{1,2, *}$ \\ Tulay Koru-Sengul ${ }^{2,3, *}$ \\ Feng Miao ${ }^{2}$ \\ Stacey L Tannenbaum² \\ Margaret M Byrne ${ }^{1-3}$ \\ Frederick Moffat ${ }^{1,2}$ \\ Alan Livingstone ${ }^{1,2}$ \\ Dido Franceschi ${ }^{1,2}$ \\ 'Division of Surgical Oncology at \\ Department of Surgery, ${ }^{2}$ Sylvester \\ Comprehensive Cancer Center, \\ ${ }^{3}$ Department of Public Health \\ Sciences, University of Miami - Miller \\ School of Medicine, Miami, FL, USA \\ *These authors contributed equally to \\ this work
}

Correspondence: Eli Avisar

Division of Surgical Oncology, University of Miami - Miller School of Medicine, Jackson Memorial Hospital/Sylvester Comprehensive Cancer Center, I I 20 NW 14th Street, CRB C232, Miami, FL 33136, USA

Tel +l 3052434902

Fax +I 3052434907

Email eavisar@med.miami.edu
Introduction: Contralateral prophylactic mastectomy (CPM) is an option for women who wish to reduce their risk of breast cancer or its local recurrence. There is limited data on demographic differences among patients who choose to undergo this procedure.

Methods: The population-based Florida cancer registry, Florida's Agency for Health Care Administration data, and US census data were linked and queried for patients diagnosed with invasive breast cancer from 1996 to 2009. The main outcome variable was the rate of CPM. Primary predictors were race, ethnicity, socioeconomic status (SES), marital status and insurance status.

Results: Our population was 91.1\% White and 7.5\% Black; 89.1\% non-Hispanic and 10.9\% Hispanic. Out of 21,608 patients with a single unilateral invasive breast cancer lesion, 837 (3.9\%) underwent CPM. Significantly more White than Black $(3.9 \%$ vs $2.8 \% ; P<0.001)$ and more Hispanic than non-Hispanic $(4.5 \%$ vs $3.8 \% ; P=0.0909)$ underwent CPM. Those in the highest SES category had higher rates of CPM compared to the lowest SES category $(5.3 \%$ vs $2.9 \% ; P<0.001)$. In multivariate analyses, Blacks compared to Whites $(\mathrm{OR}=0.59$, $95 \% \mathrm{CI}=0.42-0.83, P=0.002)$ and uninsured patients compared to privately insured $(\mathrm{OR}=0.60$, $95 \% \mathrm{CI}=0.36-0.98, P=0.043$ ) had significantly less CPM.

Conclusion: CPM rates were significantly different among patients of different race, socioeconomic class, and insurance coverage. This observation is not accounted for by population distribution, incidence or disease stage. More in-depth study of the causes of these disparities in health care choice and delivery is critically needed.

Keywords: breast cancer, bilateral mastectomy, cancer disparities, social factors, ethnic factors

\section{Introduction}

Contralateral prophylactic/preventive mastectomy (CPM) patients with unilateral invasive breast cancer (BC) increased in the US by $150 \%$ since 1988 , with no evidence of a geographic difference in practice or plateau effect. ${ }^{1}$ The annual incidence of contralateral breast cancer (CBC) is $0.5 \%$ to $0.75 \%,{ }^{1}$ but has now radically decreased with the recent use of newer therapies such as Tamoxifen, aromatase inhibitors, Trastuzumab and neo/adjuvant chemotherapy. ${ }^{2-5}$ Even in subgroups thought to be at higher risk for $\mathrm{CBC}$, such as those younger than 45 years and those with lobular histologies, the actuarial $\mathrm{CBC}$ rate at 10 years remains $<7 \%{ }^{2}$ At present, the only two groups of women at a substantially increased risk of $\mathrm{CBC}$ are those with $B R C A$ mutations, ${ }^{6}$ and women with a history of mantle irradiation during childhood and adolescence. ${ }^{?}$ 
A Cochrane Review published by Lostumbo et al ${ }^{8}$ found that although CPM reduces the risk of developing $\mathrm{CBC}$, there is insufficient evidence that CPM improves survival. Although it is unclear why the aggressive and irreversible procedure of CPM is growing in prevalence, speculation includes that greater awareness and availability of genetic testing may be responsible, but this is uncertain. ${ }^{1,9,10}$ In a recent study on 2,504 patients using multivariate logistic regression to identify independent predictors of CPM, 30.6\% of patients $<50$ years of age underwent CPM compared with only $18.2 \%$ of women $\geq 50$ years of age (odds ratio $[\mathrm{OR}]=2.2$ ). They were more likely to be surgeon identified, White race $(\mathrm{OR}=3.3)$, have a family history of $\mathrm{BC}(\mathrm{OR}=2.9)$, have invasive lobular histology, be able to have immediate reconstruction (OR $=3.3$ ), and have multicentric disease. Most of these women did not have positive genetic mutation findings. ${ }^{9}$ Another study suggested increased rates of CPM were associated with having a female surgeon. ${ }^{11,12}$

However, these previous studies were not performed using large comprehensive databases. Therefore, the current study explored factors associated with use of CPM in a large enriched population-based cancer registry database which included demographic, clinical and co-morbidity factors. The main aim of this study was to determine which demographic and social factors were associated with receipt of CPM. As previous research has shown that disparities in treatments and procedures in the care of $\mathrm{BC}$ patients (eg, time to initiation of chemotherapy ${ }^{13}$ or adjuvant radiation, and use of breast conserving surgery) $)^{14-16}$ are associated with race, ethnicity, socioeconomic status (SES) and insurance status, ${ }^{17-19}$ we were particularly interested in exploring the association of these variables with receipt of CPM. Our secondary aim was to investigate clinical (treatment and hospital characteristics) and comorbidity associations with CPM surgery.

\section{Materials and methods}

Our study used data from three sources to investigate CPM in patients with invasive BC. The Florida Cancer Data System (FCDS), a population-based Florida cancer registry, was used to identify BC patients diagnosed from 1996 to 2009. Florida's Agency for Health Care Administration (AHCA) database provided procedure and diagnoses information from all in- and out-patient facilities, and data from the US census provided a proxy for individual SES. Female patients who were 18 years or older were included if they resided in Florida during the study period. Patients with carcinoma in situ or with missing data on surgery (bilateral or unilateral), race, ethnicity, SES, marital status or insurance status were excluded from the study. Patients with unilateral BC were identified by having a single record of malignant neoplasm of the breast with diagnostic code 174 (2012 version of International Classification of Diseases, Ninth Revision (ICD-9)). Patients with more than one 174 code either with the same date or different dates were assumed to be multifocal, bilateral, or recurrent BC, and were excluded from the study. As the majority of patients receive surgical treatment at the time of diagnosis, patients receiving CPM later in the course of their disease were not included in this study.

The dichotomous primary outcome variable was whether the patient had CPM (yes/no). Patients' sociodemographic variables were age at diagnosis, race (White, Black, other), ethnicity (Hispanic and non-Hispanic), neighborhood SES based on percent of individuals living below the federal poverty line from US census tract-level information (lowest SES $\geq 20 \%$, middle-low $\geq 10 \%$ and $<20 \%$, middle-high [ $\geq 5 \%$ and $<10 \%$ ], or highest $<5 \%$ ), marital status (never married, married, or divorced/separated/widowed), primary payer at diagnosis (private insurance, Medicare, Medicaid, defense/military, Indian Health Service, other insurance, or uninsured), urban or rural geographic residence (by zip code), and characteristics of the treating facility (teaching vs non-teaching hospital and high vs low volume hospital). Clinical characteristics included tumor and treatment related variables such as the Surveillance, Epidemiology, and End Results (SEER) stage, histological differentiation grade, and history of chemotherapy or radiation. Finally, comorbidities were available for all patients based on ICD-9 diagnoses.

\section{Statistical analysis}

Demographic and clinical characteristics of patients were calculated as frequencies and percentages for categorical variables and means and standard deviations (Std) for continuous variables, and compared for all patients in the population, and then for patients with unilateral and CPM. To assess what demographics and clinical factors were significantly associated with having a CPM, multivariate logistic regression models using generalized estimation equations were fitted. Robust standard errors were calculated to take into account clustering of patients within facilities. The first multivariate model (Model 1) included covariates for sociodemographic and clinical variables; the second multivariate model (Model 2) included all diagnostic information to fully adjust for other co-morbidities. Adjusted ORs, corresponding 95\% confidence intervals ( $95 \% \mathrm{CIs}$ ), and $P$-values were calculated from these models. Statistical significance was considered at $P<0.05$. All statistical analyses were performed 
using SAS v 9.3 for Windows (SAS Institute Inc., Cary, NC, USA). The study was approved by the Institutional Review Boards of both University of Miami and Florida Department of Health.

\section{Results}

Between 1996 and 2009, 54,275 women were diagnosed with invasive BC and underwent a unilateral or CPM. Of these, 32,667 records had no data on whether there was unilateral or bilateral disease, race, ethnicity, SES, marital status, or insurance status, and therefore these cases were excluded from the analyses, for a final sample of 21,608 patients with unilateral disease and a record of the type of surgery. Descriptive statistics for demographics characteristics are provided for overall sample and by laterality of procedure done (Table 1). Mean age at diagnosis of all patients was 67.5 years $(\mathrm{Std}=13.9)$. The majority of patients were White $(19,684 ; 91.1 \%)$, while 1,625 (7.5\%) were Black, and 299 (1.4\%) were other races. Non-Hispanics $(19,257 ; 89.1 \%)$ outnumbered the Hispanics $(2,351 ; 10.9 \%)$. There were $719(3.3 \%)$ uninsured patients, $642(3 \%)$ on Medicaid compared to 6,342 (29.4\%) with private insurance and 11,778 (54.5\%) on Medicare.

Of the 21,608 patients in our population, all with a single unilaterally diagnosed lesion, 837 (3.9\%) underwent bilateral mastectomy. Those who had CPM were significantly younger ( mean $=56.9$ years, $\mathrm{SD}=14.2$ ) than those who had a unilateral procedure $($ mean $=68$ years, $\mathrm{SD}=13.7)$. Only $2.8 \%$ of Black patients had CPM as compared to $3.9 \%$ of White patients $(P<0.001)$. Lower rates of CPM were seen in non-Hispanic patients $(3.8 \%)$ compared to Hispanics $(4.5 \%)$. There was a monotonic relationship between SES and rate of CPM, with CPM increasing from $2.9 \%$ in the lowest SES up to $5.3 \%$ in the highest SES $(P<0.001)$.

Clinical characteristics of all patients and patients with unilateral and CPM are shown in Table 2. Patients undergoing CPM have lower rates of four or more comorbid conditions than those undergoing unilateral procedures $(40.6 \%$ vs $58.1 \%$ ) and are more likely to get adjuvant chemotherapy $(23.7 \%$ vs $11.7 \%)$, but are similar on other clinical and pathological characteristics.

In the multivariate logistic regression model without comorbidities (Table 3; Model 1), Black patients were less likely than Whites to have CPM (OR $=0.55,95 \% \mathrm{CI}=0.39-0.78$, $P<0.001)$. Those in the highest SES category were more likely to have CPM compared with lowest $\mathrm{SES}$ category $(\mathrm{OR}=1.37$, $95 \% \mathrm{CI}=1.06-1.76, P=0.016$ ). Uninsured patients had significantly lower rates of CPM as compared with privately insured patients $(\mathrm{OR}=0.58,95 \% \mathrm{CI}=0.36-0.95, P=0.029)$. As patients aged they were less likely to undergo this surgery (OR $=0.95,95 \% \mathrm{CI}=0.94-0.96, P<0.001)$. The characteristics of the facility where patients were treated also played a significant role, as patients at non-teaching compared to teaching ( $\mathrm{OR}=0.69,95 \% \mathrm{CI}=0.49-0.99, P=0.042)$ and low compared to high volume hospitals $(\mathrm{OR}=0.53,95 \% \mathrm{CI}=0.39-0.72$, $P<0.001$ ) had significantly lower rates of CPM. Finally, those patients with an SEER graded tumor stage of regional, lymph nodes only, had almost a $25 \%$ lower rate of CPM as compared to patients with localized disease $(\mathrm{OR}=0.78,95 \%$ $\mathrm{CI}=0.62-0.98, P=0.03)$.

When co-morbidities were included in the multivariate analysis (Table 3; Model 2), the only results that changed in a substantative way, ie, went from significant to non-significant, were that patients at non-teaching hospitals no longer had significantly lower CPM rates $(P=0.091)$ and patients with a SEER stage of regional, lymph nodes only, no longer had lower rates than those with localized disease, indicating that once comorbidities were controlled for, patients with a worse tumor stage were no longer more likely to receive CPM. We also were able to investigate whether any comorbidities were associated with receipt of CPM. We found that two comorbidities were associated with a higher likelihood of CPM: fluid and electrolyte disorder $(\mathrm{OR}=1.23,95 \% \mathrm{CI}=1.01-1.49$, $P=0.038)$ and depression $(\mathrm{OR}=1.52,95 \% \mathrm{CI}=1.24-1.85$, $P<0.001)$; and two were associated with a lower rate of CPM: deficiency anemia $(\mathrm{OR}=0.64,95 \% \mathrm{CI}=0.43-0.95, P=0.028)$ and neurological disorders $(\mathrm{OR}=0.66,95 \% \mathrm{CI}=0.45-0.99$, $P=0.44$ ) (results not shown in table). Throughout the period of data collection, the rates of CPM are about 2\% from 1996 to 2000 but increase up to $8 \%$ in 2008 (Table 4).

\section{Discussion}

In this study using large, comprehensive databases, we found a number of associations between demographics characteristics and the likelihood of undergoing CPM. For example, we found that Black women were significantly less likely than Whites to undergo CPM. This may be due to physician differential advice on risks and benefits of this procedure or system issues such as access. Previous studies of clinicians' prescription and treatment behavior have revealed racial differences in the treatment of breast carcinoma, as well as other conditions for Black patients, including neoadjuvant therapy for esophageal and gastric cancer, chronic cardiac conditions, and lower extremity amputation for peripheral vascular disease. ${ }^{17,18,20-35}$

We found that age, SES, and insurance status were associated with which patients were more likely to receive 
Table I Sociodemographic characteristics of female breast cancer patients from the Florida Cancer Data System and Agency for Health Care Administration datasets (1996-2009)

\begin{tabular}{|c|c|c|c|c|c|c|c|c|}
\hline & \multirow{2}{*}{\multicolumn{2}{|c|}{ All female patients }} & \multicolumn{6}{|c|}{ Laterality of procedure done } \\
\hline & & & \multicolumn{3}{|c|}{ Unilateral } & \multicolumn{3}{|c|}{ Bilateral } \\
\hline & $\mathbf{n}$ & Column \% & $\mathbf{n}$ & Column \% & Row \% & $\mathbf{n}$ & Column \% & Row \% \\
\hline All & 21,608 & 100.0 & 20,771 & 100.0 & 96.1 & 837 & 100.0 & 3.9 \\
\hline \multicolumn{9}{|l|}{ Race } \\
\hline White & 19,684 & 91.1 & 18,919 & 91.1 & 96.1 & 765 & 91.4 & 3.9 \\
\hline Black & 1,625 & 7.5 & 1,579 & 7.6 & 97.2 & 46 & 5.5 & 2.8 \\
\hline Other & 299 & 1.4 & 273 & 1.3 & 91.3 & 26 & 3.1 & 8.7 \\
\hline \multicolumn{9}{|l|}{ Hispanic origin } \\
\hline Non-Hispanic & 19,257 & 89.1 & 18,526 & 89.2 & 96.2 & 731 & 87.3 & 3.8 \\
\hline Hispanic & 2,351 & 10.9 & 2,245 & 10.8 & 95.5 & 106 & 12.7 & 4.5 \\
\hline \multicolumn{9}{|l|}{ Race and ethnicity } \\
\hline White/Non-Hispanic & 17,408 & 80.6 & 16,747 & 80.6 & 96.2 & 661 & 79.0 & 3.8 \\
\hline White/Hispanic & 2,276 & 10.5 & 2,172 & 10.5 & 95.4 & 104 & 12.4 & 4.6 \\
\hline Black/Non-Hispanic & I,577 & 7.3 & $|, 53|$ & 7.4 & 97.1 & 46 & 5.5 & 2.9 \\
\hline Black/Hispanic & 48 & 0.2 & 48 & 0.2 & 100.0 & & & \\
\hline Other/Non-Hispanic & 272 & 1.3 & 248 & 1.2 & 91.2 & 24 & 2.9 & 8.8 \\
\hline Other/Hispanic & 27 & 0.1 & 25 & 0.1 & 92.6 & 2 & 0.2 & 7.4 \\
\hline \multicolumn{9}{|l|}{ SES } \\
\hline Lowest & 2,628 & 12.2 & 2,553 & 12.3 & 97.1 & 75 & 9.0 & 2.9 \\
\hline Middle-low & 6,597 & 30.5 & 6,376 & 30.7 & 96.6 & 221 & 26.4 & 3.4 \\
\hline Middle-high & 7,926 & 36.7 & 7,623 & 36.7 & 96.2 & 303 & 36.2 & 3.8 \\
\hline Highest & 4,457 & 20.6 & 4,219 & 20.3 & 94.7 & 238 & 28.4 & 5.3 \\
\hline \multicolumn{9}{|l|}{ Marital status } \\
\hline Never married & 2,227 & 10.3 & 2,129 & 10.2 & 95.6 & 98 & 11.7 & 4.4 \\
\hline Married & 11,240 & 52.0 & 10,700 & 51.5 & 95.2 & 540 & 64.5 & 4.8 \\
\hline Divorced/separated/widowed & 8,141 & 37.7 & 7,942 & 38.2 & 97.6 & 199 & 23.8 & 2.4 \\
\hline \multicolumn{9}{|l|}{ Primary payer at diagnosis } \\
\hline Uninsured & 719 & 3.3 & 690 & 3.3 & 96.0 & 29 & 3.5 & 4.0 \\
\hline Private insurance & 6,342 & 29.4 & 5,906 & 28.4 & 93.1 & 436 & 52.1 & 6.9 \\
\hline Medicaid & 642 & 3.0 & 613 & 3.0 & 95.5 & 29 & 3.5 & 4.5 \\
\hline Medicare & $\mathrm{I} 1,778$ & 54.5 & 11,538 & 55.5 & 98.0 & 240 & 28.7 & 2.0 \\
\hline Defense/military/veteran & 206 & 1.0 & 196 & 0.9 & 95.1 & 10 & 1.2 & 4.9 \\
\hline Indian health services & 41 & 0.2 & 39 & 0.2 & 95.1 & 2 & 0.2 & 4.9 \\
\hline Insurance, NOS & 1,880 & 8.7 & 1,789 & 8.6 & 95.2 & 91 & 10.9 & 4.8 \\
\hline \multicolumn{9}{|l|}{ Tobacco use } \\
\hline Never & 11,148 & 51.6 & 10,719 & 51.6 & 96.2 & 429 & 51.3 & 3.8 \\
\hline History & 3,876 & 17.9 & 3,707 & 17.8 & 95.6 & 169 & 20.2 & 4.4 \\
\hline Current & $2,34 I$ & 10.8 & 2,246 & 10.8 & 95.9 & 95 & 11.4 & 4.1 \\
\hline Unknown & 4,243 & 19.6 & 4,099 & 19.7 & 96.6 & 144 & 17.2 & 3.4 \\
\hline \multicolumn{9}{|l|}{ Urban/rural living } \\
\hline Rural & 1,383 & 6.4 & $\mathrm{I}, 35 \mathrm{I}$ & 6.5 & 97.7 & 32 & 3.8 & 2.3 \\
\hline Urban & 20,225 & 93.6 & 19,420 & 93.5 & 96.0 & 805 & 96.2 & 4.0 \\
\hline \multicolumn{9}{|l|}{ Teaching hospital } \\
\hline No & 19,470 & 90.1 & 18,792 & 90.5 & 96.5 & 678 & 81.0 & 3.5 \\
\hline Yes & 2,138 & 9.9 & 1,979 & 9.5 & 92.6 & 159 & 19.0 & 7.4 \\
\hline \multicolumn{9}{|l|}{ Hospital volume } \\
\hline Low & 13,474 & 62.4 & 13,125 & 63.2 & 97.4 & 349 & 41.7 & 2.6 \\
\hline High & 8,134 & 37.6 & 7,646 & 36.8 & 94.0 & 488 & 58.3 & 6.0 \\
\hline
\end{tabular}

Notes: SES, neighborhood SES was based on percent of individuals living below the federal poverty line from US census tract-level information: lowest ( $\geq 20 \%$ ), middle-low ( $\geq 10 \%$ and $<20 \%$ ), middle-high ( $\geq 5 \%$ and $<10 \%$ ), or highest $(<5 \%$ ).

Abbreviations: SES, socioeconomic status; NOS, not otherwise specified.

a CPM. For SES in the fully adjusted model, we found that patients living in highest SES neighborhoods had a $38 \%$ greater likelihood of undergoing CPM compared with the lowest SES. Whether this is a reflection of education of that group or access to health care cannot be concluded from analyses of our large dataset. Older patients were less likely to undergo CPM, but it is unclear if this is related to higher anxiety in younger women, different 
Table 2 Clinical and pathological characteristics of female breast cancer patients in Florida (1996-2009)

\begin{tabular}{|c|c|c|c|c|c|c|c|c|}
\hline & \multirow{2}{*}{\multicolumn{2}{|c|}{ All female patients }} & \multicolumn{6}{|c|}{ Laterality of procedure done } \\
\hline & & & \multicolumn{3}{|c|}{ Unilateral } & \multicolumn{3}{|c|}{ Bilateral } \\
\hline & $\mathbf{n}$ & Column \% & $\mathbf{n}$ & Column \% & Row \% & $\mathbf{n}$ & Column \% & Row \% \\
\hline All & 21,608 & 100.0 & 20,771 & 100.0 & 96.1 & 837 & 100.0 & 3.9 \\
\hline \multicolumn{9}{|l|}{ Elixhauser co-morbidity count } \\
\hline None & 454 & 2.1 & 417 & 2.0 & 91.9 & 37 & 4.4 & 8.1 \\
\hline $1-2$ & 3,719 & 17.2 & 3,479 & 16.7 & 93.5 & 240 & 28.7 & 6.5 \\
\hline $3-4$ & 5,027 & 23.3 & 4,807 & 23.1 & 95.6 & 220 & 26.3 & 4.4 \\
\hline$>4$ & 12,408 & 57.4 & 12,068 & 58.1 & 97.3 & 340 & 40.6 & 2.7 \\
\hline \multicolumn{9}{|l|}{ Surveillance, Epidemiology, and End Results stage } \\
\hline Unknown/unstaged & $\mathrm{I}, 072$ & 5.0 & $\mathrm{I}, 036$ & 5.0 & 96.6 & 36 & 4.3 & 3.4 \\
\hline Localized & 15,380 & 71.2 & 14,750 & 71.0 & 95.9 & 630 & 75.3 & 4.1 \\
\hline Regional, direct extension \pm lymph nodes & 1,068 & 4.9 & 1,039 & 5.0 & 97.3 & 29 & 3.5 & 2.7 \\
\hline Regional, lymph nodes only & 3,675 & 17.0 & 3,544 & I7.| & 96.4 & $|3|$ & 15.7 & 3.6 \\
\hline Distant & 413 & 1.9 & 402 & 1.9 & 97.3 & 11 & 1.3 & 2.7 \\
\hline \multicolumn{9}{|l|}{ Histological grade } \\
\hline Unknown/not stated & 3,849 & 17.8 & 3,710 & 17.9 & 96.4 & 139 & 16.6 & 3.6 \\
\hline Well-differentiated & 3,836 & 17.8 & 3,677 & 17.7 & 95.9 & 159 & 19.0 & 4.1 \\
\hline Moderately differentiated & 8,121 & 37.6 & 7,805 & 37.6 & 96.1 & 316 & 37.8 & 3.9 \\
\hline Poorly differentiated & 5,507 & 25.5 & 5,294 & 25.5 & 96.1 & 213 & 25.4 & 3.9 \\
\hline Undifferentiated & 295 & 1.4 & 285 & 1.4 & 96.6 & 10 & 1.2 & 3.4 \\
\hline \multicolumn{9}{|l|}{ Histological type } \\
\hline Ductal carcinoma & 15,836 & 73.3 & 15,223 & 73.3 & 96.1 & 613 & 73.2 & 3.9 \\
\hline Lobular carcinoma & 3,612 & 16.7 & 3,443 & 16.6 & 95.3 & 169 & 20.2 & 4.7 \\
\hline Other & 2,160 & 10.0 & 2,105 & 10.1 & 97.5 & 55 & 6.6 & 2.5 \\
\hline \multicolumn{9}{|l|}{ Adjuvant chemotherapy } \\
\hline Unknown & 1,002 & 4.6 & 969 & 4.7 & 96.7 & 33 & 3.9 & 3.3 \\
\hline No & 17,988 & 83.2 & 17,382 & 83.7 & 96.6 & 606 & 72.4 & 3.4 \\
\hline Yes & 2,618 & 12.1 & 2,420 & 11.7 & 92.4 & 198 & 23.7 & 7.6 \\
\hline \multicolumn{9}{|l|}{ Adjuvant radiation therapy } \\
\hline Unknown & 621 & 2.9 & 605 & 2.9 & 97.4 & 16 & 1.9 & 2.6 \\
\hline No & 16,670 & 77.1 & 15,912 & 76.6 & 95.5 & 758 & 90.6 & 4.5 \\
\hline Yes & 4,317 & 20.0 & 4,254 & 20.5 & 98.5 & 63 & 7.5 & 1.5 \\
\hline \multicolumn{9}{|l|}{ Death within 30 days of surgery } \\
\hline No & 21,482 & 99.4 & 20,647 & 99.4 & 96.1 & 835 & 99.8 & 3.9 \\
\hline Yes & 126 & 0.6 & 124 & 0.6 & 98.4 & 2 & 0.2 & 1.6 \\
\hline \multicolumn{9}{|l|}{ Survival status } \\
\hline Dead & $4,87 \mid$ & 22.5 & 4,803 & 23.1 & 98.6 & 68 & 8.1 & 1.4 \\
\hline Alive & 16,737 & 77.5 & 15,968 & 76.9 & 95.4 & 769 & 91.9 & 4.6 \\
\hline
\end{tabular}

self-image in older women, or some other factor. Finally, uninsured patients in our study were less likely to have CPM compared with those patients who are privately insured; whether this is related to access to care or patient preference is unclear.

Hospital characteristics were also found to be significant predictors of CPM in our study. In the model adjusted for all covariates other than comorbidities, those treated in nonteaching hospitals were less likely to have CPM than those in teaching hospitals. This became non-significant when co-morbidities were added to the model. However, those in low vs high volume hospitals remained less likely to undergo CPM in the fully adjusted model controlling for comorbidities. This could be an admission rate bias or a lower threshold in high volume centers where more complex procedures are embarked upon more frequently.

A novel finding for us was that a few comorbidities were associated with a statistically significant incidence of CPM; the strongest association was with major depression where patients with depression were over $50 \%$ more likely to undergo $\mathrm{CPM}(\mathrm{OR}=1.52 ; 95 \% \mathrm{CI}=1.24-1.85, P<0.001)$. The limited research that has been done on the psychosocial implications of the preventive surgery suggests that prophylactic mastectomy may be effective in reducing distress levels in high-risk women. ${ }^{36-39}$ Therefore, it may be that a higher likelihood of undergoing CPM is associated with a larger fear of CBC and higher levels of distress and depression after a diagnosis of unilateral breast cancer. Conversely, those with deficiency 
Table 3 Multivariate logistic regression models for the primary binary outcome of undergoing bilateral mastectomy from the FCDS and AHCA datasets (1996-2009)

\begin{tabular}{|c|c|c|c|c|c|}
\hline \multirow[t]{2}{*}{ Variable } & \multirow[t]{2}{*}{ Category } & \multicolumn{2}{|l|}{ Model I } & \multicolumn{2}{|l|}{ Model 2* } \\
\hline & & OR $(95 \% \mathrm{Cl})$ & $P$-value & OR $(95 \% \mathrm{Cl})$ & $P$-value \\
\hline \multirow[t]{3}{*}{ Race } & White & 1.00 (reference) & & $\mathrm{I} .00(\mathrm{ref})$ & \\
\hline & Black & $0.55(0.39,0.78)$ & $<0.001$ & $0.59(0.42,0.83)$ & 0.002 \\
\hline & Other & $1.27(0.83,1.93)$ & 0.270 & I.3I $(0.87,1.99)$ & 0.200 \\
\hline \multirow[t]{2}{*}{ Hispanic } & Non-Hispanic & $\mathrm{I} .00(\mathrm{ref})$ & & $\mathrm{I} .00$ (ref) & \\
\hline & Hispanic & I $(0.78,1.27)$ & 0.972 & $0.99(0.79,1.25)$ & 0.965 \\
\hline \multirow[t]{4}{*}{ SES } & Lowest & $\mathrm{I} .00$ (ref) & & $\mathrm{I} .00(\mathrm{ref})$ & \\
\hline & Middle-low & $\mathrm{I} .08(0.83, \mathrm{I} .4 \mathrm{I})$ & 0.551 & $\mathrm{I} .09(0.83, \mathrm{I} .4 \mathrm{I})$ & 0.545 \\
\hline & Middle-high & $1.15(0.85,1.56)$ & 0.352 & $1.16(0.86,1.58)$ & 0.329 \\
\hline & Highest & $1.37(1.06,1.76)$ & 0.016 & $1.38(1.07,1.8)$ & 0.014 \\
\hline Age at diagnosis & Years & $0.95(0.94,0.96)$ & $<0.001$ & $0.95(0.94,0.96)$ & $<0.001$ \\
\hline \multirow[t]{3}{*}{ Marital status } & Never married & $\mathrm{I} .00(\mathrm{ref})$ & & $\mathrm{I} .00(\mathrm{ref})$ & \\
\hline & Married & $1.07(0.84,1.37)$ & 0.573 & $\mathrm{I} .08(0.85, \mathrm{I} .38)$ & 0.519 \\
\hline & Divorced/separated/widowed & $0.99(0.76,1.27)$ & 0.908 & $0.99(0.76,1.28)$ & 0.931 \\
\hline Primary payer & Private insurance & 1.00 (ref) & & $1.00($ ref $)$ & \\
\hline \multirow[t]{6}{*}{ at diagnosis } & Uninsured & $0.58(0.36,0.95)$ & 0.029 & $0.60(0.36,0.98)$ & 0.043 \\
\hline & Medicaid & $0.83(0.59,1.17)$ & 0.292 & $0.81(0.57,1.15)$ & 0.230 \\
\hline & Medicare & $0.86(0.67,1.11)$ & 0.248 & $0.86(0.67,1.11)$ & 0.249 \\
\hline & Defense/military/veteran & $0.81(0.46,1.45)$ & 0.482 & $0.80(0.45,1.42)$ & 0.440 \\
\hline & Indian/public & $0.72(0.24,2.11)$ & 0.547 & $0.66(0.22,1.97)$ & 0.461 \\
\hline & Insurance, NOS & $0.70(0.55,0.89)$ & 0.004 & $0.7(0.55,0.89)$ & 0.003 \\
\hline Urban/rural & Urban & 1.00 (ref) & & $1.00($ ref $)$ & \\
\hline living & Rural & $0.83(0.55,1.25)$ & 0.371 & $0.82(0.54,1.25)$ & 0.355 \\
\hline Teaching & Teaching hospital & $\mathrm{I} .00(\mathrm{ref})$ & & $1.00(\mathrm{ref})$ & \\
\hline hospital & Non-teaching hospital & $0.69(0.49,0.99)$ & 0.042 & $0.73(0.5 \mathrm{I}, \mathrm{I} .05)$ & 0.091 \\
\hline Hospital & High & $1.00(\mathrm{ref})$ & & $\mathrm{I} .00(\mathrm{ref})$ & \\
\hline volume & Low & $0.53(0.39,0.72)$ & $<0.001$ & $0.53(0.4,0.72)$ & $<.001$ \\
\hline Surveillance, & Localized & $\mathrm{I} .00(\mathrm{ref})$ & & 1.00 (ref) & \\
\hline Epidemiology, and & Regional, direct extension \pm lymph nodes & $0.93(0.67,1.28)$ & 0.651 & $0.99(0.7,1.4)$ & 0.969 \\
\hline \multirow[t]{2}{*}{ End Results stage } & Regional, lymph nodes only & $0.78(0.62,0.98)$ & 0.030 & $0.85(0.64,1.14)$ & 0.276 \\
\hline & Distant & $0.83(0.45,1.55)$ & 0.568 & $0.94(0.46,1.91)$ & 0.862 \\
\hline
\end{tabular}

Notes: *Model 2 also includes comorbidities. OR $(95 \% \mathrm{Cl})$ : Odds ratio and $95 \%$ confidence interval. SES = neighborhood SES was based on percent of individuals living below the federal poverty line from US census tract-level information: lowest ( $\geq 20 \%$ ), middle-low ( $\geq 10 \%$ and $<20 \%)$, middle-high ( $\geq 5 \%$ and $<10 \%$ ), or highest ( $<5 \%$ ).

Abbreviations: FCDS, Florida Cancer Data System; AHCA, Florida's Agency for Health Care Administration; SES, socioeconomic status; NOS, not otherwise specified.

Table 4 Rates of CPM (1996-2009)

\begin{tabular}{|c|c|c|c|c|c|}
\hline & & \multicolumn{2}{|l|}{ No } & \multicolumn{2}{|l|}{ Yes } \\
\hline & & $\bar{n}$ & $\%$ & $\mathbf{n}$ & $\%$ \\
\hline \multicolumn{6}{|l|}{ CPM } \\
\hline All & 21,608 & 20,771 & 96.1 & 837 & 3.9 \\
\hline \multicolumn{6}{|c|}{ Year of diagnosis } \\
\hline 1996 & 1,640 & 1,604 & 97.8 & 36 & 2.2 \\
\hline 1997 & $\mathrm{I}, 054$ & 1,032 & 97.9 & 22 & 2.1 \\
\hline 1998 & 1,069 & 1,046 & 97.8 & 23 & 2.2 \\
\hline 1999 & $|, 3| 4$ & $\mathrm{I}, 287$ & 97.9 & 27 & 2.1 \\
\hline 2000 & $|, 22|$ & 1,200 & 98.3 & 21 & 1.7 \\
\hline 2001 & 1,210 & $|| 8 \mid$, & 97.6 & 29 & 2.4 \\
\hline 2002 & $\mathrm{I}, 30 \mathrm{I}$ & 1,267 & 97.4 & 34 & 2.6 \\
\hline 2003 & $\mathrm{I}, 478$ & 1,437 & 97.2 & 41 & 2.8 \\
\hline 2004 & $\mathrm{I}, 482$ & $|, 43|$ & 96.6 & 51 & 3.4 \\
\hline 2005 & I,972 & I,907 & 96.7 & 65 & 3.3 \\
\hline 2006 & 1,920 & 1,828 & 95.2 & 92 & 4.8 \\
\hline 2007 & 1,902 & $\mathrm{I}, 80 \mathrm{I}$ & 94.7 & 101 & 5.3 \\
\hline 2008 & 2,011 & I,879 & 93.4 & 132 & 6.6 \\
\hline 2009 & 2,034 & |,87| & 92.0 & 163 & 8.0 \\
\hline
\end{tabular}

Abbreviation: CPM, contralateral prophylactic mastectomy. anemia $(\mathrm{OR}=0.64,95 \% \mathrm{CI}=0.43-0.95, P=0.028)$ or neurological disorders $(\mathrm{OR}=0.66,95 \% \mathrm{CI}=0.45-0.99, P=0.44)$, were approximately $35 \%$ less likely to undergo CPM; this may stem from a clinical recognition of these patients being less suitable for the more extensive surgery.

Limitations of this study include a relatively small sample size for appropriate subgroup analysis and the lack of data about the presence of BRCA deleterious mutations. Also, the FCDS and AHCA databases do not contain accurate or sufficient information on hormone receptor-negative status of tumors, and therefore, we were unable to explore the association of estrogen/progesterone receptors or triple negative patients with receipt of CPM. Finally, detailed information on additional risk factors such as number and degree of affected relatives or opportunities for nonsurgical risk reduction are not available in the databases. Nonetheless, this study is based on a large statewide cancer registry database and allows us 
to examine a wide variety of associations of demographic, clinical and comorbid characteristics, with choice of CPM. Thus, it paves the way for subsequent studies that will look more in depth into factors affecting whether patients undergo CPM, in order to ensure treatment equality for all patients.

In conclusion, CPM rates reveal significant differences among patients of different race, socioeconomic class, and insurance coverage. The reasons for these differences as well as the rising rates of CPM in the face of lack of evidence of survival benefits remain unexplained. It seems that personal and psychosocial factors are driving the choices about this treatment. It may be that more public health education is needed to better inform patients in their decision making process. Health care delivery systems optimization for more equitable and accessible delivery of breast cancer care, at the same standard, to different socioeconomic classes of patients, at different geographical locations, and regardless of insurance status, should be planned and attempted. More in-depth study of the causes of these disparities is critically needed so as to guide future planning for health care delivery in this area.

\section{Acknowledgment}

Funding source: James and Esther King Florida Biomedical Research Program (Grant 10KG-06).

\section{Disclosure}

There are no financial disclosures or conflicts of interest to report for any of the authors.

\section{References}

1. Tuttle TM, Habermann EB, Grund EH, Morris TJ, Virnig BA. Increasing use of contralateral prophylactic mastectomy for breast cancer patients: a trend toward more aggressive surgical treatment. J Clin Oncol. 2007;25(33):5203-5209.

2. Gao X, Fisher SG, Emami B. Risk of second primary cancer in the contralateral breast in women treated for early-stage breast cancer: a populationbased study. Int J Radiat Oncol Biol Phys. 2003;56(4): 1038-1045.

3. Early Breast Cancer Trialists' Collaborative Group (EBCTCG). Effects of chemotherapy and hormonal therapy for early breast cancer on recurrence and 15-year survival: an overview of the randomised trials. Lancet. 2005;365(9472):1687-1717.

4. Arimidex, Tamoxifen, Alone or in Combination (ATAC) Trialists' Group, Forbes JF, Cuzick J, et al. Effect of anastrozole and tamoxifen as adjuvant treatment for early-stage breast cancer: 100-month analysis of the ATAC trial. Lancet Oncol. 2008;9(1):45-53.

5. Romond EH, Perez EA, Bryant J, et al. Trastuzumab plus adjuvant chemotherapy for operable HER2-positive breast cancer. $N$ Engl J Med. 2005;353(16):1673-1684

6. Metcalfe K, Lynch HT, Ghadirian P, et al. Contralateral breast cancer in BRCA1 and BRCA2 mutation carriers. J Clin Oncol. 2004;22(12): 2328-2335.

7. Dores GM, Anderson WF, Beane Freeman LE, Fraumeni JF Jr, Curtis RE. Risk of breast cancer according to clinicopathologic features among long-term survivors of Hodgkin's lymphoma treated with radiotherapy. Br J Cancer. 2010;103(7):1081-1084.
8. Lostumbo L, Carbine NE, Wallace J. Prophylactic mastectomy for the prevention of breast cancer. Cochrane Database Syst Rev. 2010;11: CD002748.

9. Yi M, Hunt KK, Arun BK, et al. Factors affecting the decision of breast cancer patients to undergo contralateral prophylactic mastectomy. Cancer Prev Res (Phila). 2010;3(8):1026-1034.

10. Tuttle TM, Jarosek S, Habermann EB, et al. Increasing rates of contralateral prophylactic mastectomy among patients with ductal carcinoma in situ. J Clin Oncol. 2009;27(9):1362-1367.

11. King TA, Sakr R, Patil S, et al. Clinical management factors contribute to the decision for contralateral prophylactic mastectomy. J Clin Oncol. 2011;29(16):2158-2164.

12. Arrington AK, Jarosek SL, Virnig BA, Habermann EB, Tuttle TM. Patient and surgeon characteristics associated with increased use of contralateral prophylactic mastectomy in patients with breast cancer. Ann Surg Oncol. 2009;16(10):2697-2704.

13. Vandergrift JL, Niland JC, Theriault RL, et al. Time to adjuvant chemotherapy for breast cancer in National Comprehensive Cancer Network institutions. J Natl Cancer Inst. 2013;105(2):104-112.

14. Satariano ER, Swanson GM, Moll PP. Nonclinical factors associated with surgery received for treatment of early-stage breast cancer. $\mathrm{Am} \mathrm{J}$ Public Health. 1992;82(2):195-198.

15. Yood MU, Johnson CC, Blount A, et al. Race and differences in breast cancer survival in a managed care population. $J$ Natl Cancer Inst. 1999;91(17):1487-1491.

16. Michalski TA, Nattinger AB. The influence of black race and socioeconomic status on the use of breast-conserving surgery for Medicare beneficiaries. Cancer. 1997;79(2):314-319.

17. Breen N, Wesley MN, Merrill RM, Johnson K. The relationship of socio-economic status and access to minimum expected therapy among female breast cancer patients in the National Cancer Institute BlackWhite Cancer Survival Study. Ethn Dis. 1999;9(1):111-125.

18. Harris DR, Andrews R, Elixhauser A. Racial and gender differences in use of procedures for black and white hospitalized adults. Ethn Dis. 1997;7(2):91-105.

19. Smith RG, Landry JC, Hughes LL, et al. Conservative treatment of early-stage breast cancer in a medically indigent population. $J$ Natl Med Assoc. 1995;87(7):500-504.

20. Dignam JJ. Differences in breast cancer prognosis among AfricanAmerican and Caucasian women. CA Cancer J Clin. 2000;50(1): $50-64$.

21. Eley JW, Hill HA, Chen VW, et al. Racial differences in survival from breast cancer. Results of the National Cancer Institute Black/White Cancer Survival Study. JAMA. 1994;272(12):947-954.

22. Heimann R, Ferguson D, Powers C, Suri D, Weichselbaum RR, Hellman S. Race and clinical outcome in breast cancer in a series with long-term follow-up evaluation. J Clin Oncol. 1997;15(6): 2329-2337.

23. Velanovich V, Yood MU, Bawle U, et al. Racial differences in the presentation and surgical management of breast cancer. Surgery. 1999;125(4):375-379.

24. Dignam JJ, Redmond CK, Fisher B, Costantino JP, Edwards BK. Prognosis among African-American women and white women with lymph node negative breast carcinoma: findings from two randomized clinical trials of the National Surgical Adjuvant Breast and Bowel Project (NSABP). Cancer. 1997;80(1):80-90.

25. Muss HB, Hunter CP, Wesley M, et al. Treatment plans for black and white women with stage II node-positive breast cancer. The National Cancer Institute Black/White Cancer Survival Study experience. Cancer. 1992;70(10):2460-2467.

26. Wojcik BE, Spinks MK, Optenberg SA. Breast carcinoma survival analysis for African American and white women in an equal-access health care system. Cancer. 1998;82(7):1310-1318.

27. Lindau ST, Tomori $\mathrm{C}, \mathrm{McCarville} \mathrm{MA}$, Bennett CL. Improving rates of cervical cancer screening and Pap smear follow-up for low-income women with limited health literacy. Cancer Invest. 2001;19(3): 316-323. 
28. Howard DL, Penchansky R, Brown MB. Disaggregating the effects of race on breast cancer survival. Fam Med. 1998;30(3):228-235.

29. Petersen LA, Wright SM, Peterson ED, Daley J. Impact of race on cardiac care and outcomes in veterans with acute myocardial infarction. Med Care. 2002;40(Suppl 1):I86-I96.

30. Collins TC, Johnson M, Henderson W, Khuri SF, Daley J. Lower extremity nontraumatic amputation among veterans with peripheral arterial disease: is race an independent factor? Med Care. 2002; 40(Suppl 1):I106-I116.

31. Dominitz JA, Maynard C, Billingsley KG, Boyko EJ. Race, treatment, and survival of veterans with cancer of the distal esophagus and gastric cardia. Med Care. 2002;40(Suppl 1):I14-I26.

32. Wenneker MB, Epstein AM. Racial inequalities in the use of procedures for patients with ischemic heart disease in Massachusetts. JAMA. 1989;261(2):253-257.

33. van Ryn M. Research on the provider contribution to race/ethnicity disparities in medical care. Med Care. 2002;40(Suppl 1):I140-I151.
34. Council on Ethical and Judicial Affairs. Black-white disparities in health care. JAMA. 1990;263(17):2344-2346.

35. Dignam JJ, Colangelo L, Tian W, et al. Outcomes among AfricanAmericans and Caucasians in colon cancer adjuvant therapy trials: findings from the National Surgical Adjuvant Breast and Bowel Project. J Natl Cancer Inst. 1999;91(22):1933-1940.

36. Metcalfe KA. Prophylactic bilateral mastectomy for breast cancer prevention. J Womens Health (Larchmt). 2004;13(7):822-829.

37. Jatoi I, Becher H, Leake CR. Widening disparity in survival between white and African-American patients with breast carcinoma treated in the US Department of Defense Healthcare system. Cancer. 2003;98(5):894-899.

38. Li BD, Brown WA, Ampil FL, Burton GV, Yu H, McDonald JC. Patient compliance is critical for equivalent clinical outcomes for breast cancer treated by breast-conservation therapy. Ann Surg. 2000;231(6):883-889.

39. Joslyn SA. Racial differences in treatment and survival from early-stage breast carcinoma. Cancer. 2002;95(8):1759-1766.

\section{Dovepress}

\section{Publish your work in this journal}

Breast Cancer: Targets and Therapy is an international, peerreviewed open access journal focusing on breast cancer research, identification of therapeutic targets and the optimal use of preventative and integrated treatment interventions to achieve improved outcomes, enhanced survival and quality of life for the cancer patient.

View the full aims and scopes of this journal here. The manuscript management system is completely online and includes a very quick and fair peer-review system, which is all easy to use. Visit http:// www.dovepress.com/testimonials.php to read real quotes from published authors. 